\title{
Some Ions of TNAZ - A DFT Study
}

\section{Lemi Türker}

Department of Chemistry, Middle East Technical University, Üniversiteler, Eskişehir Yolu No: 1, 06800 Çankaya/Ankara, Turkey; e-mail: 1turker@gmail.com; lturker@metu.edu.tr

\begin{abstract}
TNAZ is a thermally stable high energy explosive molecule. In the present study, some ionic forms of it have been investigated within the limitations of density functional theory at the level of UB3LYP/6-311++G(d,p). Various properties (including structural, electronic, spectral and quantum chemical) are obtained and discussed.
\end{abstract}

\section{Introduction}

1,3,3-trinitroazetidine, also known as TNAZ, is an energetic small-ring compound which is one of the most widely studied (theoretically and experimentally) explosive recently [1-4]. The driving impetus is due to ongoing research to get more powerful but meantime more insensitive explosives. It possesses three nitro groups $\left(\mathrm{N}-\mathrm{NO}_{2}\right.$ and two $\left.\mathrm{C}-\mathrm{NO}_{2}\right)$ on four membered azetidine ring (a nitrogen heterocyclic ring). It possesses improved performance in comparison to conventional melt castable explosive trinitrotoluene (TNT). The presence of small strained ring system, due to ring strain contributes some additional energy [5-10]. The literature has various methods reported for the synthesis of 1,3,3-trinitroazetidine [11].

Due to its high performance and melt castable properties, TNAZ has been proposed as potential replacement for TNT [12]. The low melting point of TNAZ $\left(101^{\circ} \mathrm{C}\right)$ enables the processing of formulations on modified production lines. Its performance is approximately $30 \%$ greater than TNT. It also shows excellent thermal stability $\left(>180^{\circ} \mathrm{C}\right)[13,14]$ besides its many extra advantages over the already known explosives. TNAZ has a detonation velocity between 8.6 and $8.85 \mathrm{~km} / \mathrm{sec}$, and generates a pressure of $372 \mathrm{kbar}$. One measured value for the detonation velocity was $8.73 \mathrm{~km} / \mathrm{sec}$. TNAZ is a highly energetic material (more powerful than RDX) but less

Received: August 6, 2021; Accepted: September 11, 2021

Keywords and phrases: TNAZ, 1,3,3-trinitroazetidine, explosive, ions, spark sensitivity.

Copyright (C) 2021 Lemi Türker. This is an open access article distributed under the Creative Commons Attribution License, which permits unrestricted use, distribution, and reproduction in any medium, provided the original work is properly cited. 
vulnerable than most other nitramines $[15,16]$. TNAZ has solubility in molten TNT (in contrast to HMX) and is compatible with aluminum, steel, brass and glass [17-19]. By using the pressure DSC method, the compatibility of 1,3,3-trinitroazetidine (TNAZ) with various energetic components and inert materials of solid propellants was studied [20]. On the theoretical ground, desensitization of TNAZ via molecular structure modification has been investigated [21].

By means of molecular dynamics simulation with the ReaxFF/lg reactive force field, reactive molecular dynamics simulations of the thermal decomposition mechanism of 1,3,3trinitroazetidine has been studied where the thermal decomposition of TNAZ crystals at high temperature was calculated [22]. Then, the authors succeeded to analyze all of the change in the potential energy of TNAZ, the formation of small-molecule products and clusters, and the initial reaction path of TNAZ. Thus, the kinetic parameters of different reaction stages in thermal decomposition of TNAZ were obtained [22]. Some empirical methods for estimating the detonation properties of energetic TNAZ molecular derivatives have been reported [23].

In the present study, some charged forms of TNAZ molecule have been considered within the constraints of density functional theory (DFT) and the effect of perturbation on various properties of perturbed TNAZ systems have been investigated.

\section{Method of Calculation}

The geometry optimizations of all the structures leading to energy minima were achieved initially by using MM2 method followed by semi-empirical PM3 self-consistent fields molecular orbital (SCF MO) method [24,25] at the unrestricted level [26,27]. Subsequent optimizations were achieved at Hartree-Fock level using various basis sets. Then, geometry optimizations were managed within the framework of density functional theory $[28,29]$ at the level of UB3LYP/6$311++G(d, p)[26,30]$. The exchange term of B3LYP consists of hybrid Hartree-Fock and local spin density (LSD) exchange functions with Becke's gradient correlation to LSD exchange [29,31]. Note that the correlation term of B3LYP consists of the Vosko, Wilk, Nusair (VWN3) local correlation functional [32] and Lee, Yang, Parr (LYP) correlation correction functional [33]. The vibrational analyses were also performed. The total electronic energies are corrected for the zero point vibrational energy (ZPE). The normal mode analysis for each structure has yielded no imaginary frequencies for the $3 N-6$ vibrational degrees of freedom, where $N$ is the number of atoms in the system. This indicates that the structure of each molecule corresponds to at least a local minimum on the potential energy surface. All these calculations were done by using the Spartan 06 package program [34]. 


\section{Results and Discussion}

Some explosives are highly affected in electrostatic fields or electrostatic charging resulting in changes in performance which sometimes causes their explosions. Ionic forms are the extreme state of electrostatic charging of materials. Electric spark which is a result of the accumulated charge may have sufficient energy to initiate explosions because of their low ionization energy. Some explosives in ionized form undergo bond-cleavage of molecular structure which may accompany or not by an explosion. Also, depending on the structure or nature of the explosives, some can tolerate negative but not positive (or vice versa) charging up to a certain extent.

In the present study, charging of TNAZ molecule has been investigated theoretically. Figure 1 shows the optimized structures of TNAZ ions considered. Note that dication of TNAZ molecule has undergone break down at the early stages of the optimization process. The figure also displays the direction of the dipole moment vectors.
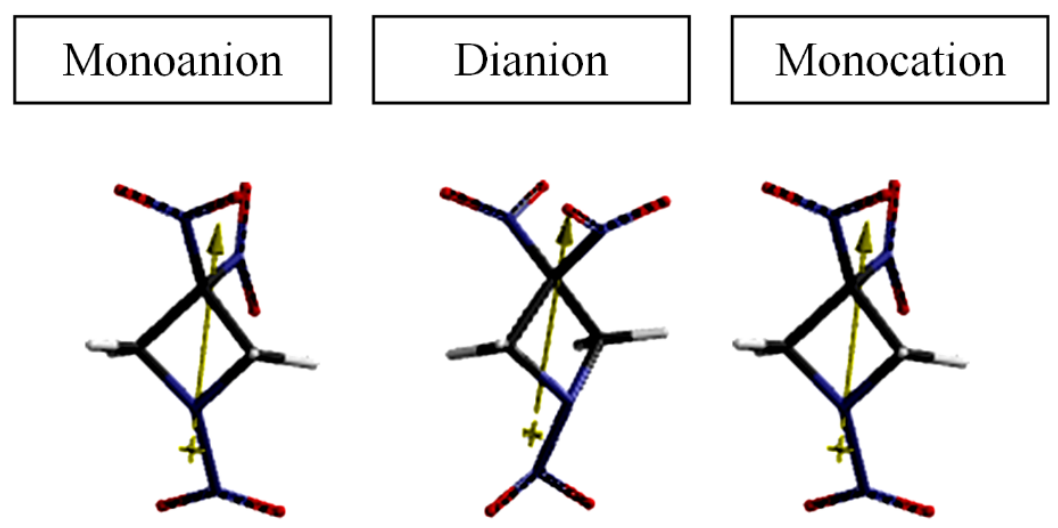

Figure 1. Optimized structures of the ions considered.

Figure 2 shows the calculated bond lengths of the ions considered. In the monoanion case, as seen in the figure, one of the $\mathrm{C}-\mathrm{NO}_{2}$ bonds has been highly elongated ( $2.26 \AA$ ) as compared to the other one $(1.37 \AA)$. The literature value of the respective type of bond length varies between 1.517 $\AA$ (dimethyldinitromethane) and $1.526 \AA$ (tetranitromethane) [35]. However, in the dianion case both of the $\mathrm{C}-\mathrm{NO}_{2}$ bonds are very comparable and at reasonable lengths (1.49 and $1.50 \AA$ ). This fact brings to mind that some balance in the charge distribution between the $\mathrm{C}-\mathrm{NO}_{2}$ groups should have occurred. Indeed this is the case (see Figure 3). However a question arises whether the dianion formation can occur instantaneously without passing through the mono anion formation first. The bond lengths of the ring atoms are quite irresponsive to negative or positive charging.

The $\mathrm{N}-\mathrm{NO}_{2}$ bond in the monocation is somewhat elongated $(1.76 \AA)$ as compared to the respective bond lengths in the anions and gives the signal of $\mathrm{NO}_{2}$ expelling while the dication 
formation. Dication is decomposed while optimizing the structure, expelling the nitramine $\mathrm{NO}_{2}$ group. Note that a typical $\mathrm{N}-\mathrm{NO}_{2}$ bond length is $1.382 \AA$ (dimethylnitramine) [35].
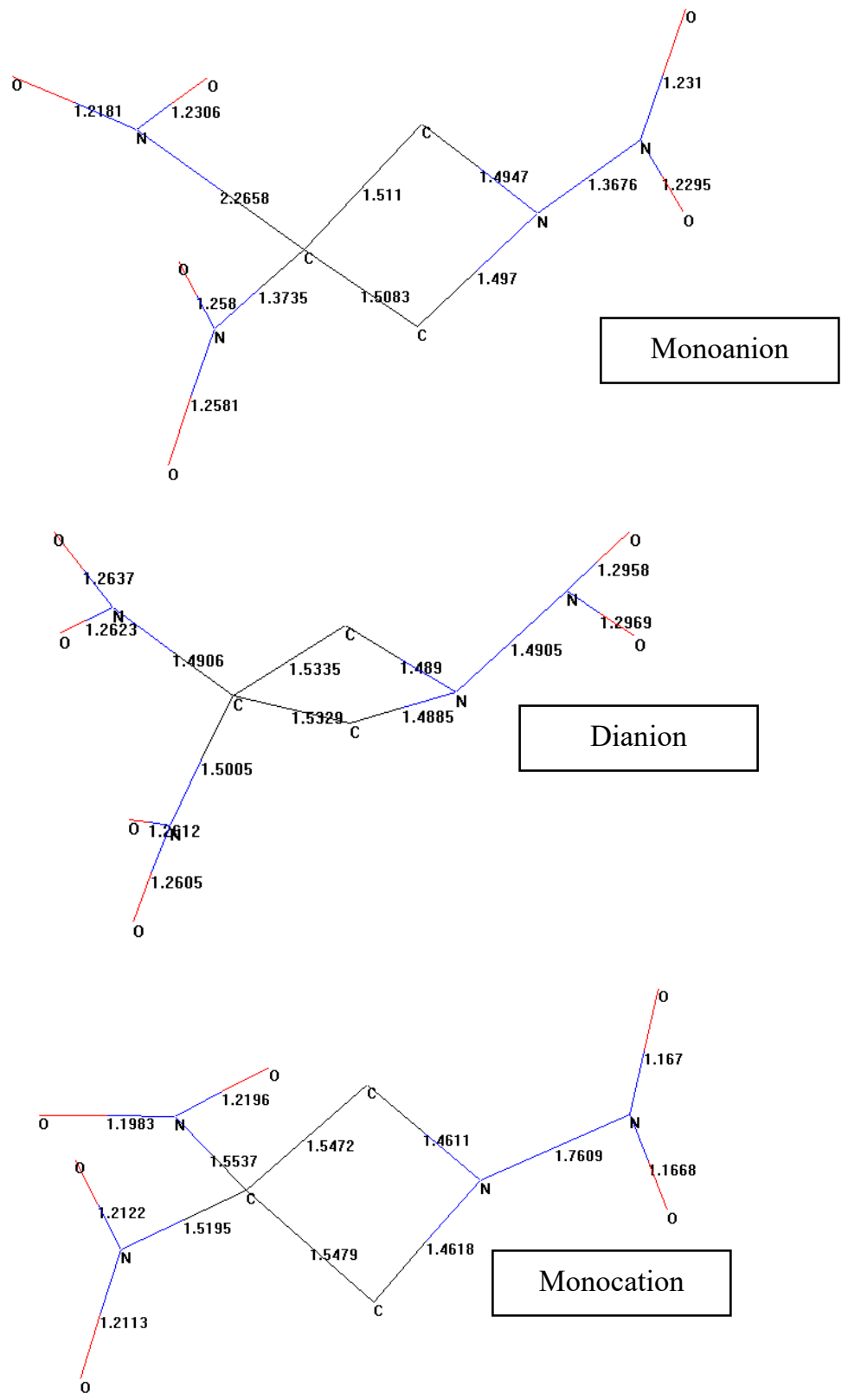

Figure 2. The calculated bond lengths of the ions considered (Hydrogens omitted).

Figure 3 shows the electrostatic potential (ESP) charges developed on the atoms of the ions considered. Note that the ESP charges are obtained by the program based on a numerical method 
that generates charges that reproduce the electrostatic potential field from the entire wavefunction [34].

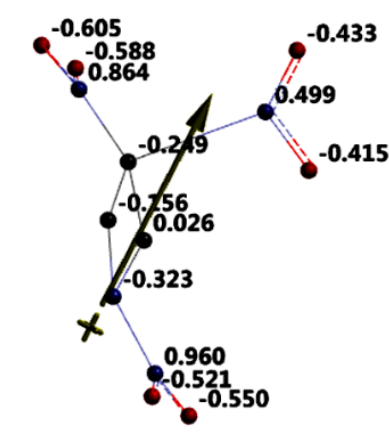

Monoanion

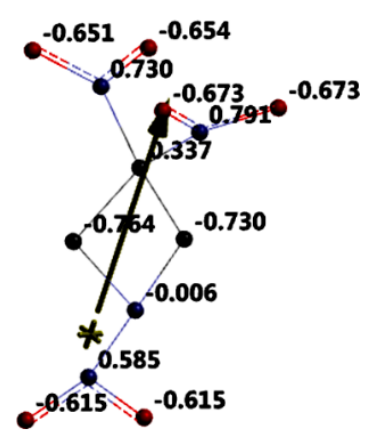

Dianion

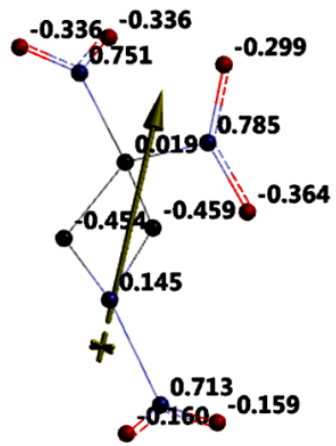

Monocation

Figure 3. The ESP charges on atoms of the ions considered.

As seen in Figure 3, in all the cases, the direction of the dipole moment vectors is from the nitramine nitrogen to somewhere nearby the $\mathrm{C}-\mathrm{NO}_{2}$ groups. The nitro groups linked to carbon atom possess a negative overall charge in the cases of mono and dianion, whereas positive charge in the monocation. As for the nitramine $\mathrm{NO}_{2}$ group, it has negative overall charge in the monoanion and the dianion cases whereas positive charge in the monocation.

Appearance of the electrostatic potential maps of the systems considered is shown in Figure 4 where normally red/reddish and blue/ green regions stand for negative and positive potential fields, respectively. In the present case, different shades of red and blue regions of the ions indicate relative negative and positive potential regions.
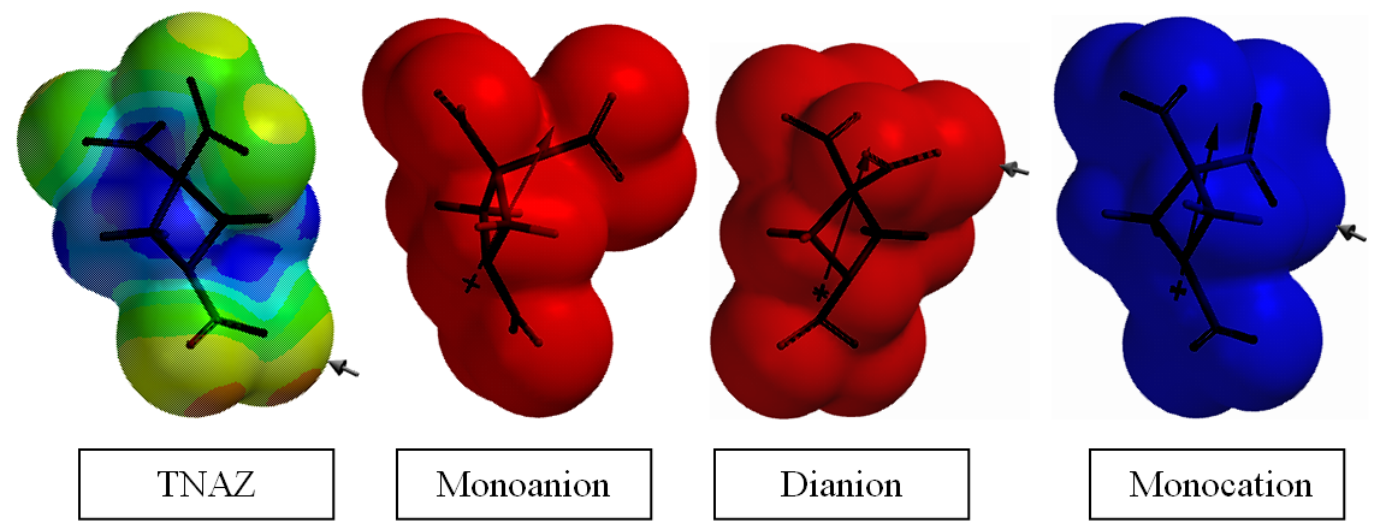

Figure 4. ESP maps of TNAZ and the ions considered. 
Table 1 shows various properties of the systems considered. As seen in the table, all the systems/ions considered have greater area and volume values compared to neutral TNAZ molecule. This could be due to repulsion of like charges happened on some sites of the molecular structure and thus some expansion of the structure. Such irregular charge distribution and bond length changes also affect the dipole moment values. Although, the ions have much greater dipole moment values compared to TNAZ itself, irregularity exists in them, such as obtained in the monoanion and dianion cases.

Table 1. Some properties of the ions considered.

\begin{tabular}{llllll}
\hline Structure & Area $\left(\AA^{2}\right)$ & Volume $\left(\AA^{\AA^{3}}\right)$ & Ovality & Polarizability & $\begin{array}{l}\text { Dipole } \\
\text { (Debye) }\end{array}$ \\
\hline TNAZ & 173.98 & 139.73 & 1.34 & 51.45 & 0.50 \\
Monoanion & 183.75 & 144.39 & 1.38 & & 4.69 \\
Dianion & 178.74 & 142.10 & 1.36 & 52.71 & 1.07 \\
Monocation & 178.33 & 141.65 & 1.36 & & 6.00 \\
\hline
\end{tabular}

Table 2 contains some energies of the systems standing for the ionic structures of TNAZ, where $\mathrm{E}, \mathrm{ZPE}$ and $\mathrm{E}_{\mathrm{C}}$ are total electronic energy, zero point vibrational energy and the corrected total electronic energy, respectively. Although the number of electrons possessed not the same, the systems corresponding to the anions seem to be electronically more stable but the monocation system is less stable than TNAZ and the dianion is less stable than the monoanion system. However, one should keep in mind that actually the monoanion system is a decomposed structure $\left(\mathrm{NO}_{2}\right.$ group expelled from the structure) and as a whole it is more stable than the dianion which holds its integrity.

Table 2. Some energies of TNAZ and the ions considered.

\begin{tabular}{lccc}
\hline Structure & $\mathbf{E}$ & $\mathbf{Z P E}$ & $\mathbf{E}_{\mathbf{C}}$ \\
\hline TNAZ & -2066133.77 & 278.31 & -2065855.46 \\
Monoanion & -2066347.50 & 264.56 & -2066082.94 \\
Dianion & -2066081.51 & 261.58 & -2065819.93 \\
Monocation & -2065121.58 & 267.19 & -2064854.39 \\
\hline
\end{tabular}

Energies in $\mathrm{kJ} / \mathrm{mol}$. 
Figure 5 displays some of the molecular orbital energy levels of the ions considered. Note that the monoanion and monocation are open-shell systems, thus the unrestricted level of calculations yield $\alpha$ - and $\beta$ - type molecular orbitals. In the figure they are labeled as a- and b-types.
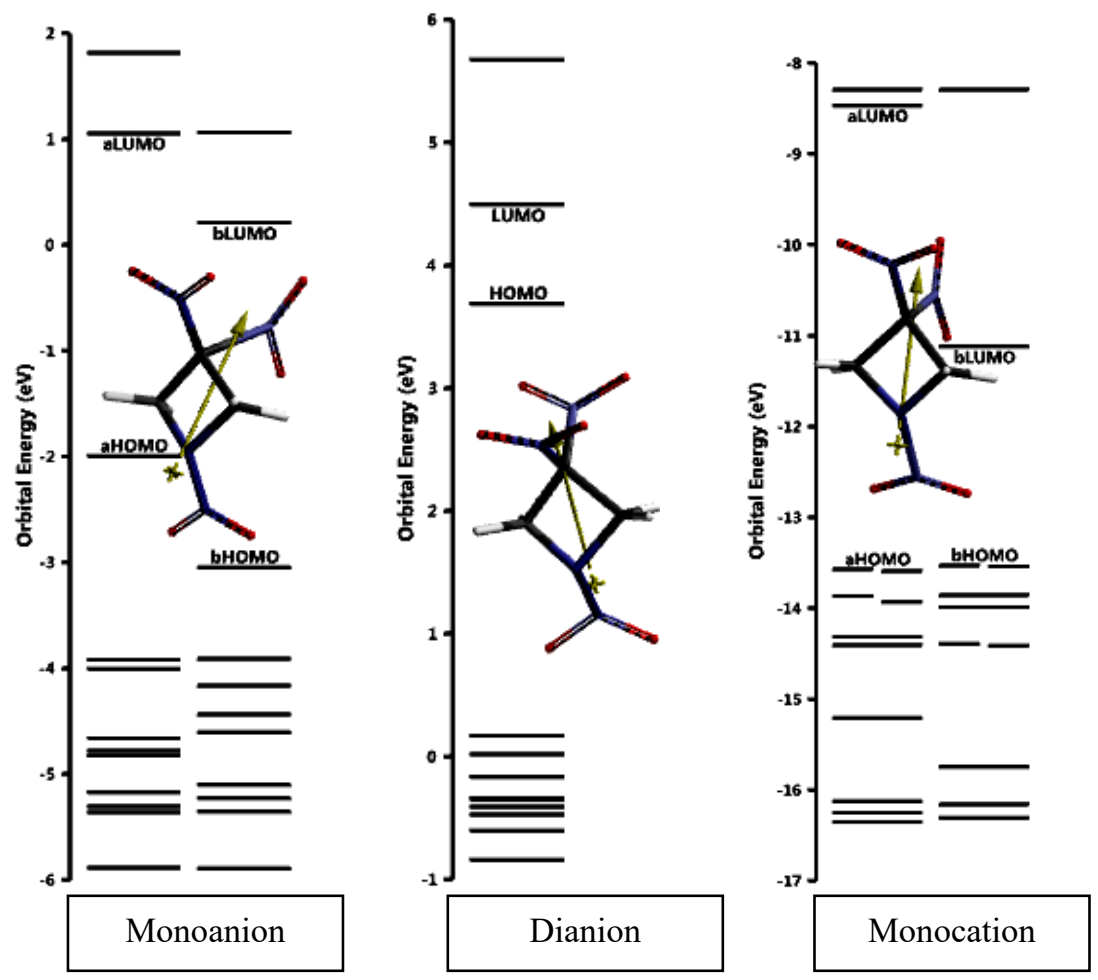

Figure 5. Some of the molecular orbital energy levels of the ions considered.

Table 3 includes the HOMO, LUMO energies and the interfrontier molecular orbital energy gap values $\left(\Delta \varepsilon=\varepsilon_{\text {LUMO }}-\varepsilon_{\text {HOMO }}\right)$ of the systems/ ions considered.

Table 3. The HOMO, LUMO energies and the FMO energy gaps of TNAZ and the ions considered.

\begin{tabular}{lccc}
\hline Structure & HOMO & LUMO & $\boldsymbol{\Delta} \boldsymbol{\varepsilon}$ \\
\hline TNAZ & -874.55 & -361.35 & 513.20 \\
Monoanion & -192.57 & 101.73 & 294.30 \\
Dianion & 355.65 & 433.62 & 77.97 \\
Monocation & -1309.37 & -817.02 & 492.35 \\
\hline
\end{tabular}

Energies in $\mathrm{kJ} / \mathrm{mol}$. 
The order of HOMO and LUMO energies is monocation $<$ TNAZ $<$ monoanion $<$ dianion. Consequently, $\Delta \varepsilon$ values follow the order of dianion $<$ monoanion $<$ monocation $<$ TNAZ. Thus, TNAZ should be less sensitive to impact stimulus than the ionic forms. Whereas the dianion is the most sensitive in the group, because the impact sensitivity has been reversely correlated with $\Delta \varepsilon$ value $[36,37]$.

Figures 6 and 7, respectively show the HOMO and LUMO patterns of the ions considered. As seen in Figure 6 the nitramine moiety contributes nil or very little in to the HOMO in the case of monoanion but appreciably in the dianion. In the case of the monocation, the nitramine moiety contributes almost none into the $\alpha$ - and $\beta$ - HOMOs.

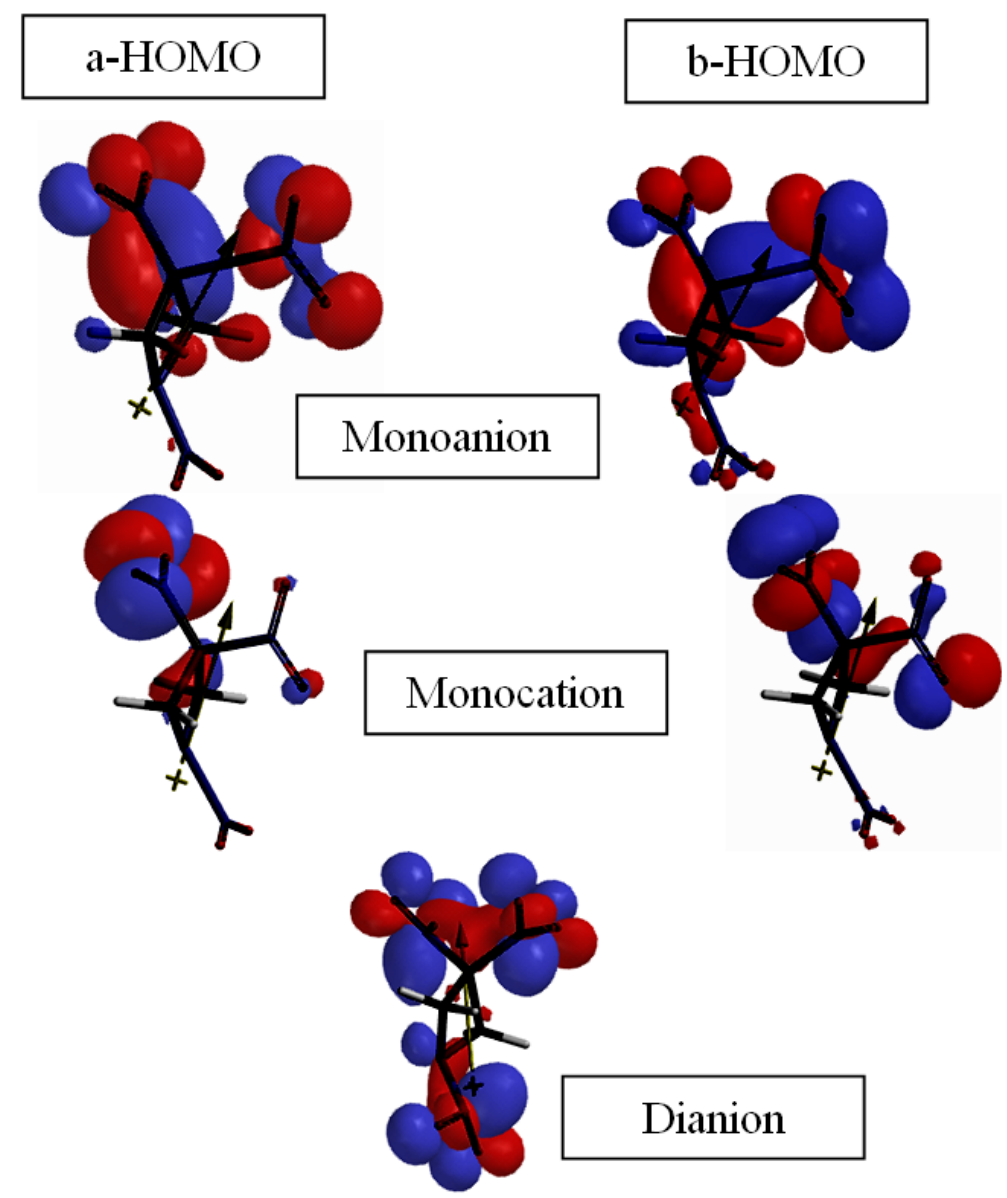

Figure 6. The HOMO patterns of the ions considered.

As seen in Figure 7, one of the C-NO $\mathrm{N}_{2}$ moieties does not contribute into the HOMO in the cases of monoanion and the monocation. 


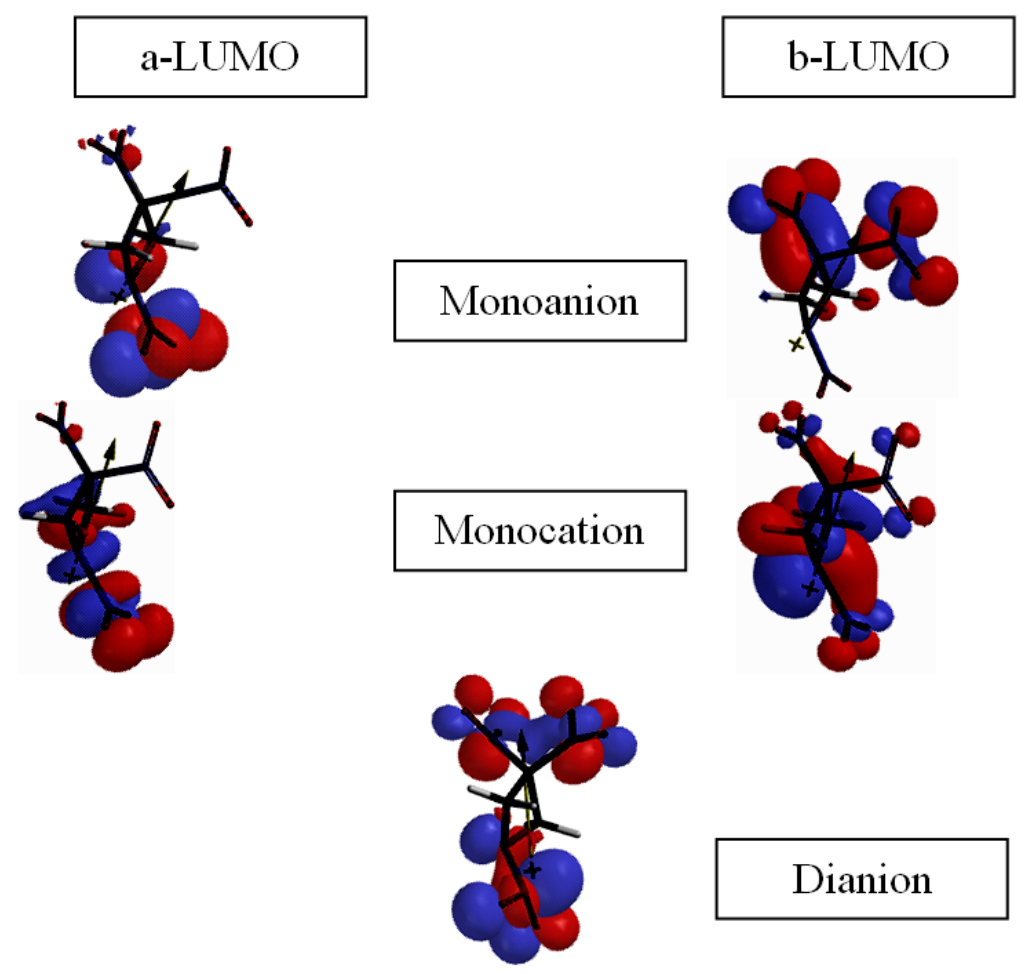

Figure 7. The LUMO patterns of the ions considered.

Figure 8 shows the time-dependent (TDDFT) UV-VIS spectra of the ions considered. As
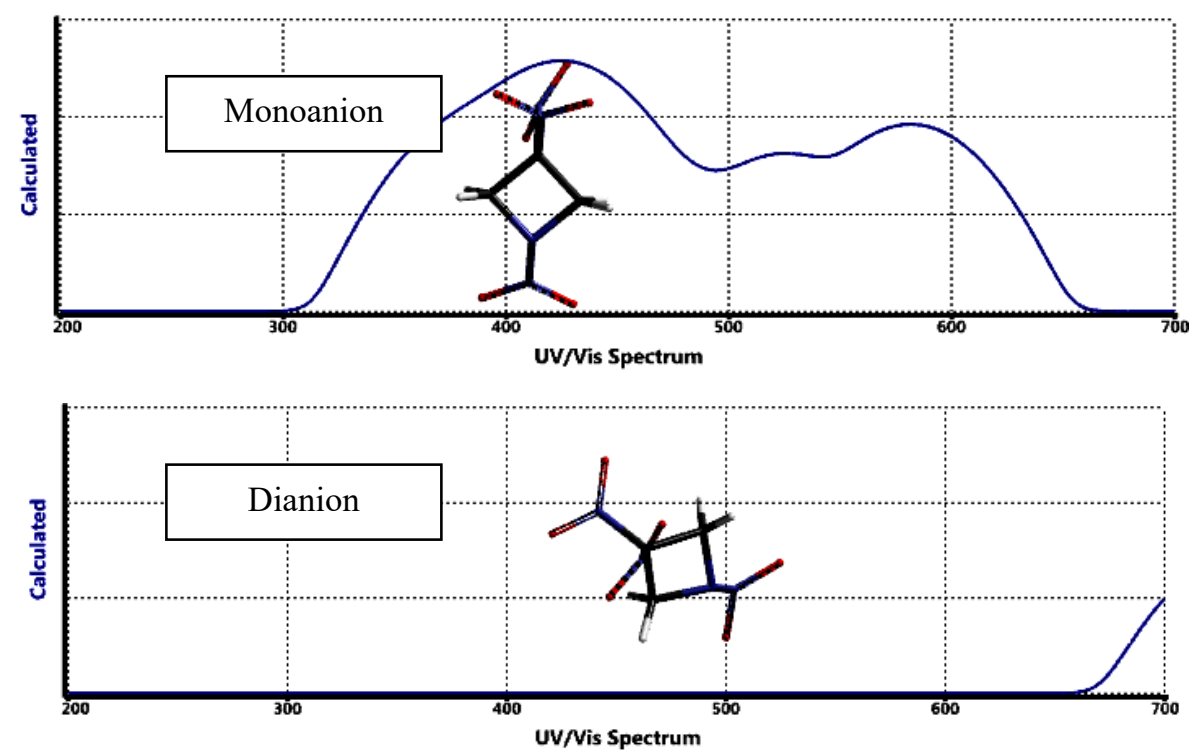


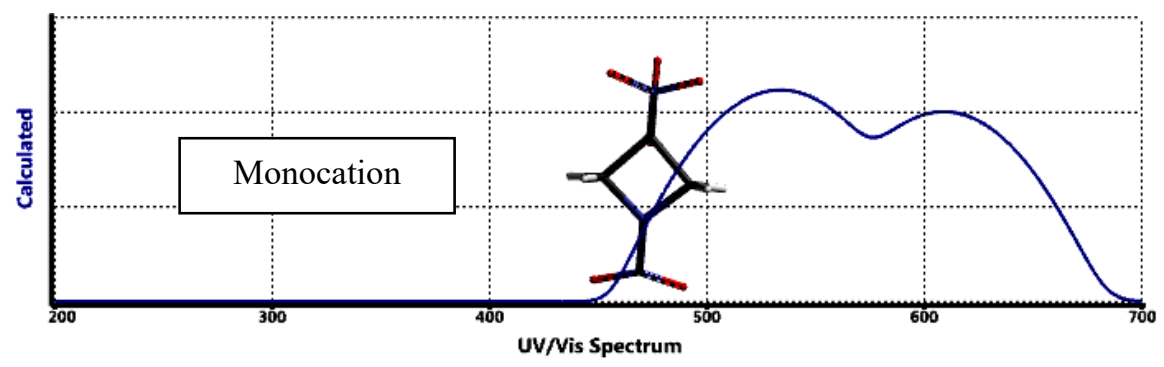

Figure 8. The calculated UV-VIS spectra of the ions considered.

compared to the monoanion, the dication formation causes an appreciable bathochromic shift. Whereas, the monocation formation yields a spectrum confined to visible part of the spectrum.

Figure 9 shows the spin density maps of the open-shell ions considered. In the monoanion case, the expelled $\mathrm{NO}_{2}$ group also has quite high spin density. Therefore, the $\mathrm{NO}_{2}$ group expelled is probably not merely an anion but a radical anion. On the other hand, the monocation has rather low spin density on the nitramine $\mathrm{NO}_{2}$ but quite high density on the ring atoms, especially on the amino nitrogen.

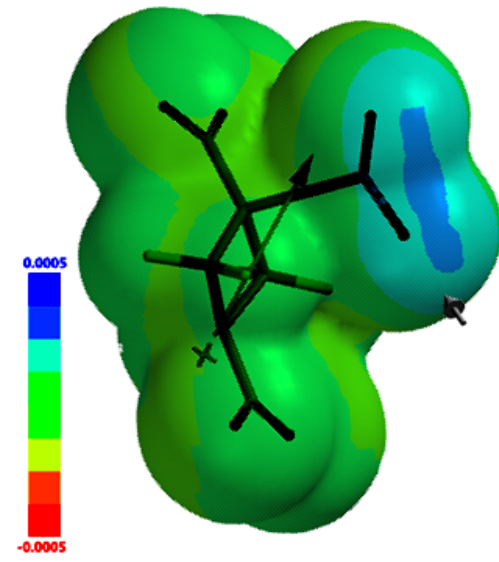

Monoanion

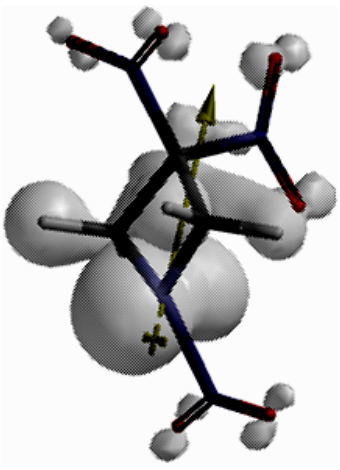

Monocation

Figure 9. Spin density maps of the open-shell ions.

\section{Conclusion}

The present density functional study on some TNAZ ions has revealed that in the case of the monoanion, one of the $\mathrm{C}-\mathrm{NO}_{2}$ bond rupture occurs. The dianion form is electronically stable. The monoanion expels one of the $\mathrm{NO}_{2}$ groups attached to the carbon atom (in the form of radical 
anion). In the case of the monocation, an elongated $\mathrm{N}^{-\mathrm{NO}_{2}}$ bond exists and the expelled $\mathrm{NO}_{2}$ group has positive overall charge and the spin density has spread mainly over the ring atoms.

All these results within the constraints of the density functional theory and the level of calculations performed suggest that TNAZ molecule may undergo various degrees of perturbation while charging.

\section{References}

[1] P.F. Pagoria, G.S. Lee, R.A. Mitchell and R.D. Schmidt, A review of energetic materials synthesis, Thermochim. Acta 384 (2002), 187-204. https://doi.org/10.1016/S0040-6031(01)00805-X

[2] H.S. Jadhav, M.B. Talawar, D.D. Dhavale, S.N. Asthana and V.V. Krishnamurthy, Alternate method to synthesis of 1,3,3-trinitroazetedine (TNAZ): Next generation melt castable high energy material, Indian J. Chemical Technology 13 (2006), 41-46.

[3] L. Türker, A composite of NTO and TNAZ - A DFT treatment, Earthline Journal of Chemical Sciences 5(2) (2021), 261-274. https://doi.org/10.34198/ejcs.5221.261274

[4] L. Türker, A DFT treatment of some aluminized 1,3,3-trinitroazetidine (TNAZ) systems - A deeper look, Earthline Journal of Chemical Sciences 3 (2) (2020), 121-140. https://doi.org/10.34198/ejcs.3220.121140

[5] T.G. Archibald, R. Gilardi, K. Baum and C.J. George, Synthesis and X-ray crystal structure of 1,3,3-trinitroazetidine, J. Org. Chem. 55 (1990), 2920-2924. https://doi.org/10.1021/jo00296a066

[6] R.L. McKenney, Jr., T.G. Floyd, W.E. Stevens, T.G. Archibald, A.P. Marchand, G.V.M. Sharma and S.G. Bott, Synthesis and thermal properties of 1,3-dinitro-3-(1',3'dinitroazetidin-3'-yl) azetidine (TNDAZ) and its admixtures with 1,3,3-trinitroazetidine (TNAZ), J. Energ. Mater. 16 (1998), 199-235. https://doi.org/10.1080/07370659808217513

[7] A.M. Hiskey, M.C. Johnson and E.D. Chavez, Preparation of 1-substituted-3,3dinitroazetidines, J. Energ. Mater. 17 (1999), 233-252. https://doi.org/10.1080/07370659908216106

[8] J. Zhang, R. Hu, C. Zhu, G. Feng and Q. Long, Thermal behavior of 1,3,3trinitroazetidine, Thermochim. Acta 298 (1997), 31-35. https://doi.org/10.1016/S0040-6031(97)00056-7

[9] S. Zeman, The thermoanalytical study of some amino derivatives of 1,3,5trinitrobenzene, Thermochim. Acta 216 (1993), 157-168. https://oi.org/10.1016/0040-6031(93)80389-R 
[10] M.H. Keshavarz, Approximate prediction of melting point of nitramines, nitrate esters, nitrate salts and nitroaliphatics energetic compounds, J. Hazard. Mater. A 138 (2006), 448-451. https://doi.org/10.1016/j.jhazmat.2006.05.097

[11] Z. Jalovy, S. Zeman, M. Suceska, P. Vavra, K. Dudek and J.M. Rajic, 1,3,3Trinitroazetidine (TNAZ). Part I. Syntheses and properties, J. Energ. Mater. 19 (2001), 219-239. https://doi.org/10.1080/07370650108216127

[12] D.S. Watt and M.D. Cliff, Evaluation of 1,3,3-trinitroazetidine (TNAZ) - A high performance melt-castable explosive, Technical Report DSTO-TR-1000, Defence Science and Technology Organization (DSTO), Aeronautical and Maritime Research Laboratory, Melbourne, Australia, 2000.

[13] A.K. Sikder and N. Sikder, A review of advanced high performance, insensitive and thermally stable energetic materials emerging for military and space applications, $J$. Hazard. Mater. A112 (2004), 1-15. https://doi.org/10.1016/j.jhazmat.2004.04.003

[14] N. Sikder, A.K. Sikder, N.R. Bulakh and B.R. Gandhe, 1,3,3-Trinitroazetidine (TNAZ), A melt-cast explosive: synthesis, characterization and thermal behaviour, Journal of Hazardous Materials 113(1-3) (2004), 35-43.

https://doi.org/10.1016/j.jhazmat.2004.06.002

[15] S. Iyer, E.Y. Sarah, M. Yoyee, R. Perz, J. Alster and D. Stoc, TNAZ based composition C-4 development, 11th Annual Working Group, Institute on Synthesis of High Density Materials (Proc.), Kiamesha Lakes, 1992.

[16] M. Oftadeh, M. Hamadanian, M. Radhoosh and M.H. Keshavarz, DFT molecular orbital calculations of initial step in decomposition pathways of TNAZ and some of its derivatives with $-\mathrm{F},-\mathrm{CN}$ and - $\mathrm{OCH} 3$ groups, Computational and Theoretical Chemistry 964 (2011), 262-268. https://doi.org/10.1016/j.comptc.2011.01.007

[17] J.O. Doali, R.A. Fifer, D.I. Kruzezynski and B.J. Nelson, The mobile combustion diagnostic fixture and its application to the study of propellant combustion Part-I. Investigation of the low pressure combustion of LOVA XM-39 Propellant, Technical Report No: BRLMR-3787/5, US Ballistic Research Laboratory, Maryland, 1989.

[18] J.P. Agrawal, Recent trends in high-energy materials, Prog. Energ. Combust. Sci. 24/1 (1998), 1-30. https://doi.org/10.1016/S0360-1285(97)00015-4

[19] M.D. Coburn, M.A. Hiskey and T.G. Archibald, Scale-up and waste-minimization of the Los Alamos process for 1,3,3-trinitroazetidine (TNAZ), Waste Management 17 (1997), 143-146. https://doi.org/10.1016/S0956-053X(97)10013-7

[20] L. Jizhen, F. Xuezhong, F. Xiping, Z. Fengqi and H. Rongzu, Compatibility study of 1,3,3-trinitroazetidine with some energetic components and inert materials, Journal of 
Thermal Analysis and Calorimetry 85(3) (2006), 779-784.

https://doi.org/10.1007/s10973-005-7370-8

[21] L. Türker and S. Varis, Desensitization of TNAZ via molecular structure modification and explosive properties - A DFT study, Acta Chim. Slov. 59 (2012), 749-759.

[22] J. Wu, Y. Huang, L. Yang, D. Geng, F. Wang, H. Wang and L. Chen, Reactive molecular dynamics simulations of the thermal decomposition mechanism of 1,3,3-trinitroazetidine, Chem. Phys. Chem. 19(20) (2018), 2683-2695. https://doi.org/10.1002/cphc.201800550

[23] M-H. Liu, C. Chen and Y-S. Hong, Empirical methods for estimating the detonation properties of energetic TNAZ molecular derivatives, Journal of Theoretical and Computational Chemistry 3(03) (2004), 379-389.

https://doi.org/10.1142/S0219633604001100

[24] J.J.P. Stewart, Optimization of parameters for semiempirical methods I. Method, $J$. Comput. Chem. 10 (1989), 209-220. https://doi.org/10.1002/jcc.540100208

[25] J.J.P. Stewart, Optimization of parameters for semi empirical methods II. Application, J. Comput. Chem. 10 (1989), 221-264. https://doi.org/10.1002/jcc.540100209

[26] A.R. Leach, Molecular Modeling, Essex: Longman, 1997.

[27] P. Fletcher, Practical Methods of Optimization, New York: Wiley, 1990.

[28] W. Kohn and L. Sham, Self-consistent equations including exchange and correlation effects, J. Phys. Rev. 140 (1965), 1133-1138. https://doi.org/10.1103/PhysRev.140.A1133

[29] R.G. Parr and W. Yang, Density Functional Theory of Atoms and Molecules, London: Oxford University Press, 1989.

[30] C.J. Cramer, Essentials of Computational Chemistry, Chichester, West Sussex: Wiley, 2004.

[31] A.D. Becke, Density-functional exchange-energy approximation with correct asymptotic behavior, Phys. Rev. A 38 (1988), 3098-3100.

https://doi.org/10.1103/PhysRevA.38.3098

[32] S.H. Vosko, L. Vilk and M. Nusair, Accurate spin-dependent electron liquid correlation energies for local spin density calculations: a critical analysis, Can. J. Phys. 58 (1980), 1200-1211. https://doi.org/10.1139/p80-159

[33] C. Lee, W. Yang and R.G. Parr, Development of the Colle-Salvetti correlation-energy formula into a functional of the electron density, Phys. Rev. B 37 (1988), 785-789. https://doi.org/10.1103/PhysRevB.37.785 
[34] SPARTAN 06, Wavefunction Inc., Irvine CA, USA, 2006.

[35] L.V. Vilkov, V.S. Mastryukov and N.I. Sadova, Determination of the Geometrical Structure of Free Molecules, Moscow: Mir, 1983.

[36] V. Anbu, K.A. Vijayalakshmi, R. Karunathan, A.D. Stephen and P.V. Nidhin, Explosives properties of high energetic trinitrophenyl nitramide molecules: A DFT and AIM analysis, Arabian Journal of Chemistry 12(5) (2019), 621-632.

https://doi.org/10.1016/j.arabjc.2016.09.023

[37] N.R. Badders, C. Wei, A.A. Aldeeb, W.J. Rogers and M.S. Mannan, Predicting the impact sensitivities of polynitro compounds using quantum chemical descriptors, Journal of Energetic Materials 24 (2006), 17-33.

https://doi.org/10.1080/07370650500374326 